\title{
Iconicity and Second Language Visual Perception: A Psycholinguistic Study of English Imitative Words at Different De-iconization Stages
}

\author{
Liubov Tkacheva ${ }^{1, *(1)}$, Maria Flaksman ${ }^{2}$, Andrey Nasledov ${ }^{1}$, Yulia Sedelkina ${ }^{3}$ and Yulia Lavitskaya ${ }^{3}$ (I) \\ 1 Department of Pedagogy and Pedagogical Psychology, Saint Petersburg State University, \\ 7/7 Universitetskaya Emb., Saint Petersburg 199034, Russia; a.nasledov@spbu.ru \\ 2 Department of Foreign Languages, Saint Petersburg State Electrotechnical University "LETI", \\ 5 Professora Popova Str., Saint Petersburg 197022, Russia; maria.alexeevna@gmail.com or \\ mariia.flaksman@uni-jena.de \\ 3 Department of Foreign Languages and Linguo-Didactics, Saint Petersburg State University, \\ $7 / 7$ Universitetskaya Emb., Saint Petersburg 199034, Russia; y.sedelkina@spbu.ru (Y.S.); \\ y.lavitskaya@spbu.ru (Y.L.) \\ * Correspondence: 1.tkachewa@spbu.ru or tkachewa.luba@gmail.com; Tel.: +7-921-326-1964
}

\section{check for} updates

Citation: Tkacheva, L.; Flaksman, M.; Nasledov, A.; Sedelkina, Y.; Lavitskaya, Y. Iconicity and Second Language Visual Perception: A Psycholinguistic Study of English Imitative Words at Different De-iconization Stages. Mathematics 2021, 9, 1331. https://doi.org/ $10.3390 /$ math 9121331

Academic Editors: Gregorio Giménez Esteban and Javier Valbuena

Received: 18 May 2021

Accepted: 7 June 2021

Published: 9 June 2021

Publisher's Note: MDPI stays neutra with regard to jurisdictional claims in published maps and institutional affiliations.

Copyright: (c) 2021 by the authors. Licensee MDPI, Basel, Switzerland. This article is an open access article distributed under the terms and conditions of the Creative Commons Attribution (CC BY) license (https:/ / creativecommons.org/licenses/by/ $4.0 /)$.

\begin{abstract}
The study of iconicity, i.e., of a link between form and meaning in a word based on similarity, has gained increased attention in recent years. Although recent research has shown an important role of iconicity for first language acquisition, its role for the second language (L2) acquisition is still unclear, neither is it understood how the perception of imitative words depends on their iconic expressiveness. We applied a multivariate experimental plan with repeated measurements and experimental and control stimuli to study visual recognition of English iconic (imitative) words at four stages of de-iconization (SDs) by native speakers of Russian $(\mathrm{N}=106)$ using a lexical decision task. The participants were presented with an experimental stimulus and had to decide as rapidly as possible whether a visually presented letter string was a word or not. The method of diachronic evaluation was used to group the pre-selected imitative words into four categories where SD-1 words are the most vivid imitative words with an evident (iconic) link between form and meaning, and SD- 4 words are the words which have lost this link in the course of language (semantic and phonetic) evolution. The findings have revealed that proceeding speed and accuracy rates are strongly connected to SDs: the less iconic (imitative) a word is, the faster and more accurately it is recognized; most iconic words (SD-1) are characterized by the slowest RTs and lowest accuracy rates. The results suggest that iconicity does affect visual recognition of imitative words by second language learners.
\end{abstract}

Keywords: de-iconization; iconicity; second language perception; L2; lexical decision; psycholinguistics; psycho-semantics

\section{Introduction}

The present research is conducted following the framework of iconicity studies. Iconicity is the resemblance-based mapping between aspects of a word's form and meaning. Iconic words encompass onomatopoeic words (like cuckoo or splash), mimetic words (mumble, bubble), phonoaesthemic words (glimmer, glow, glisten [1]), and ideophones [2] Such words are believed to constitute a minority in the language [3]. However, the recent research $[4,5]$ has shown that iconic words are by no means language marginalia. The facts that (1) they are found in languages all over the globe [6], (2) in ancient and reconstructed languages [7], (3) in invented languages [8] and (4) in child speech [9-11] suggest that iconicity is a fundamental aspect of the human communicative system. Moreover, an iconic stage is believed to be an integral part of language ontogeny and phylogeny [12].

Psycholinguistic experimental research on iconicity focuses mainly on the investigation of the perception of imitative words of unrelated languages, especially those unknown 
to the participants, and stimuli are mostly presented aurally $[13,14]$. This research is aimed to investigate the imitative words' visual recognition parameters and, thus, speculate on the topic of iconicity application in second language (L2) teaching. Iconicity is assumed to facilitate L2 word learning [15-17]. This assumption is based on the universality of imitative words which eases their understanding without prior knowledge [18], and inborn cognitive abilities of any human to coin and decipher iconic elements of the language [19].

However, psycholinguistic research on iconicity often ignores two important problems in its (possible) application. Firstly, it concentrates mainly on audial perception of iconic words $[13,16,20]$, whereas in a real-life situation, L2 learners often have to deal with various kinds of written materials. Nevertheless, experimental studies on visual perception of iconic words are scarce [21]. Secondly, iconic words themselves are not homogeneous. Both their form and meaning change over time due to systematic language transformations affecting all its vocabulary [22]. However, the extent of these transformations varies across different words. To that end, words with a different degree of de-iconization co-exist at the current stage of language evolution. Some words are more iconic and others less, i.e., exhibiting the loss of iconic (imitative) quality and, consequently, a weaker resemblance between form and meaning.

The results of our previous research using the lexical decision method [23] revealed a significant time delay in the visual recognition of iconic words in comparison with noniconic words, both in the subjects' native language (Russian) and in their foreign language (English), regardless of their age and level of foreign language proficiency $(\mathrm{N}=148)$. We suggested that the recorded delay is associated with the cognitive complexity of recognizing iconic words, which requires processing of not only semantic information, but also decoding the figurative message involving additional information proceeding and energy resources consumption. However, the degree of de-iconization [22] was not included in the experimental design, which might have been a confounding variable interfering with the results. The present study is designed to overcome this gap by including words at different stages of de-iconization.

Recent research has provided strong evidence for an important role of iconicity in all language domains $[12,19,24]$. Our study adds to the existing body of psycholinguistic research on iconicity in L1 and L2 visual recognition and written language acquisition. Some previous research has demonstrated that iconic words contribute to early vocabulary acquisition. Imai and Kita [10] found that the ontogeny stage is paramount for the development of speech competence and occurs in the pre-speech phase of children irrespective of their ethnic origin or cultural environment. These findings support the cross-modality hypothesis, according to which cross-modality forms a basis for language acquisition, i.e., all children go through an iconic (onomatopoeic, imitative) stage in their speech manifestation.

Along the same lines, a recent neurophysiologic study [9] demonstrated that 11-monthold children exhibit a high selective sensibility towards iconicity. The cross-modality hypothesis goes together with perceptual-motor analogies which ease the acquisition of iconic words and facilitate communication [25]. It was found that the more iconic the words are, the earlier they are learned by younger children [11]. Iconic words are also produced in conversation more often by both children and adults in child-directed speech. Iconicity is assumed to have such a positive effect at the earliest stages of language acquisition as it allows to eliminate referential ambiguity and to match sensory-motor linguistic processes of hearing and pronunciation [26,27]. Interestingly, the sensibility towards aurally perceived iconicity increases with age and mental development of a child and suggests the cumulative effect of linguistic experience [28]. This effect allows the didactic use of iconicity-iconic signs facilitate communication and language learning as they appeal to basic fundamental psycholinguistic processes [29].

Furthermore, the cross-linguistic universality of iconism demonstrated by the extensive research on comparative phonosemantics [2,6] suggests the presence of certain easily recognizable sound-meaning mapping patterns, which may contribute to second language 
vocabulary acquisition [30]. Some research [31,32] has shown that iconicity facilitates the understanding and memorizing of foreign words. Revill et al. [14] results demonstrated statistically reliable sensitivity in native speakers of English to aurally presented iconic words of a foreign language. Furthermore, it has been demonstrated that foreign iconic words are perceived and recognized better than non-iconic ones [33]. Another neurolinguistic research [34] provided empirical evidence for the neural basis of iconicity. The subjects showed the association between an aurally presented syllable and certain visual size. The results indicated faster and better perception under the congruent condition.

Research on visual perception of iconic words has been underrepresented in the soundsymbolism literature so far. Lockwood et al. [13] studied how Dutch speakers learned real Japanese sound-symbolic words with their actual and semantically opposite translation. The real meaning of the words showing cross-modal correspondences facilitated the learning. A subsequent forced choice task revealed that the participants were sensitive to iconic cues in ideophones, choosing the right translation from two opposite alternatives. There are another empirical data suggesting that visually perceived iconic words are understood faster and better than non-iconic words, even when they are not read aloud. This suggests that iconicity implicitly influences the evaluation of words' meanings [35]. Later, Monaghan and Fletcher [21] conducted a psycholinguistic study using an experimental design with a visual stimuli presentation of non-words investigating whether individual phonemes or phoneme features are best accounted for iconicity effects; according to their results the operation of individual phoneme to meaning relations is more important than cross-modal associations between sound and meaning.

Our study aims to advance our understanding of cognitive mechanisms of the visual recognition of English iconic words by L2 learners. Furthermore, we attempt to clarify the role of iconicity in L2 vocabulary learning. The results of the above-mentioned studies suggest the potential advantage of iconic words in lexical acquisition cross-linguistically, so recent research has been focused on measuring iconicity in the lexicon [36], at behavioral levels [37], in the perception and comprehension of iconic forms [38] and on system-wide levels [39]; however, there was no distinguishing difference between different groups of iconic words using criteria of de-iconization. The results of the present study enable us to identify the extent of iconic learning advantage, namely whether some particular groups of iconic words are easier to recognize and, hence, easier to learn. We build on the previous research by comparing the speed and accuracy of iconic words' visual recognition using the lexical decision task, but now we take into consideration their de-iconization stage. Our research hypotheses are that (1) iconic words would differ from non-iconic words in the speed and accuracy of their perception; (2) iconic words at different de-iconization stages would be recognized with different speed and accuracy; (3) there will be a gradation in the above-mentioned parameters between non-words, iconic words at different de-iconization stages, and non-iconic words. To test these hypotheses, we developed a multivariate experimental plan with repeated measurements, experimental and control stimuli and took into account interfering variables to maintain the internal validity of the experiment. The results of the present research allow to gain an insight into the role of iconic words in the language system and the cognitive mechanisms of their visual recognition, and to speculate on the topic of how iconicity may facilitate L2 word learning.

\section{Materials and Methods}

We replicated our previous study [23] using the lexical decision task [40]. However, the stimuli selection procedure was designed to overcome the shortcomings of the previous research. Specifically, to uphold internal validity of the experiment, all stimuli were controlled for length (monosyllabic), grammatical category, morphophonological structure and frequency. The experimental target stimuli were also controlled for their degree of iconicity loss and contained four groups of imitative words ( 8 words per group). The groups of non-imitative stimuli ( 32 words) and non-words (64) were used as control stimuli. The announcement of the experiment was sent out in an electronic form to graduates of the 
linguistic faculties of Russian universities. For the participation in the study, subjects were selected using a random selection method. These were the participants who met the set criteria of age, non-bilingualism, sufficient language proficiency in English and an absence of obstacles for taking part in the computerized study on time reaction during semantic stimuli visual recognition. The intended sample size was 100 participants since such a number of participants is considered as more than sufficient to obtain valid data using a multivariate experimental plan with repeated measurements [41]. A total of 106 native speakers of Russian ( $35 \mathrm{~m}, 71 \mathrm{f})$, aged between 18 and $50(\mathrm{M}=23.75$ years), participated in the experiment. All participants were asked to provide proof of their English language proficiency in the form of TOEFL, IELTS, PTE, CAE, etc. Participants gave their written informed consent prior to participating in the study, reported taking no medications that could potentially affect their reaction time, confirmed absence of mental, psychiatric or neurological disorders and having normal or corrected-to-normal vision. Each participant was financially compensated with 1000 RUB upon completion of the experiment. All the information and data exchange between the experimenters and the subjects took place remotely via email correspondence in connection with the current pandemic situation.

For imitative stimuli, the stimuli selection was performed according to the following steps. We selected words marked as 'imitative', 'onomatopoeic', 'mimetic', or 'echoic' in the etymology section of the Oxford English Dictionary (OED), the 3rd online edition (altogether 1078 tokens). After the exclusion of words marked as "dialectal" and "obsolete", a list of one-syllable imitative words was formed, which was divided into four groups according to words' SDs. The division was conducted using the method of diachronic evaluation of the imitative lexicon $[7,22]$. Table 1 sums up the criteria for distinguishing iconic words at four different SDs.

Table 1. Criteria for the classification of imitative words according to de-iconization stages (from Flaksman, 2015).

\begin{tabular}{|c|c|c|c|c|c|}
\hline \multirow{2}{*}{ Factors/SDs } & \multirow{2}{*}{ SD-1 } & \multirow{2}{*}{ SD-2 } & \multicolumn{2}{|c|}{ SD-3 } & \multirow{2}{*}{ SD-4 } \\
\hline & & & $\mathbf{a}$ & $\mathbf{b}$ & \\
\hline System integration & - & + & + & + & + \\
\hline Significant regular sound changes & - & - & + & - & + \\
\hline $\begin{array}{c}\text { Semantic shifts leading to loss of the } \\
\text { original meaning }\end{array}$ & - & - & - & + & + \\
\hline
\end{tabular}

Out of the 1078 total sound-imitative stimuli, eight words were subsequently selected for each respective SD. The mean word frequency of the experimental stimuli was calculated by using the standardized measure of frequency per million words in OED. The stimuli at four SDs have the following mean word frequency: SD-1-0.063; SD-2-0.075; SD-3; SD-4-0.375. The mean overall frequency of the iconic words constitutes 0.222 .

The group of non-imitative stimuli was used as a control group (32 words), which contained monosyllabic non-iconic words with a mean frequency of 0.8 . Another control group included non-words (64 words) constructed according to the English phonotactic rules. Each non-word stimulus matched a corresponding experimental and non-imitative item in terms of their segmental composition. Thus, a set of data contained a total of 128 items per participant (32 target stimuli and 64 control stimuli). Table 2 presents a total set of words and non-words used in the experiment. 
Table 2. Experimental Stimuli.

\begin{tabular}{ccc}
\hline Stimuli Type & Words & Corresponding Non-Words \\
\hline SD-1 ${ }^{1}$ & Bom, fie, heck, hem, ouch, phut, pooh, twee & Bemn, vea, sutt, shen, audge, fepp, tir, quow \\
\hline SD-2 $^{1}$ & Bleep, buzz, chock, frizz, hiss, hoot, puff, thud & Blait, dozz, jott, threzz, thoss, saipe, cuth, seb \\
\hline SD-3 ${ }^{1}$ & Bib, claque, clock, fluff, gag, miff, hock, swarm & Dibb, plark, clat, freff, gubb, nith, thop, thwane \\
\hline SD-4 ${ }^{1}$ & Craze, funk, mot, rook, rut, sow, stun, touch & Preeze, shunck, nair, lart, lupp, shoy, stamn, kidge \\
\hline Non-iconic words & $\begin{array}{c}\text { Balm, box, fir, frost, glen, heel, helm, hilt, hood, } \\
\text { hoof, lad, lamb, leash, lid, morph, palm, pear, pen, } \\
\text { perch, pike, pons, pore, reel, shah, shrine, shy, silt, } \\
\text { sock, stab, steak, twig, wig }\end{array}$ & $\begin{array}{c}\text { Baine, gecks, fow, shrast, drem, hile, selm, thult, } \\
\text { shud, shoof, rabb, lenn, reesh, lub, norph, parn, } \\
\text { kuy, kem, toudge, pite, kinze, cair, lile, thar, } \\
\text { shrewn, fuy, shilk, thop, speb, steat, twed, wib }\end{array}$ \\
\hline
\end{tabular}

The lexical decision task was used as an experimental data collection tool. The participants were sent the software distributive and detailed instruction on installation and participation by email after processing their personal data, confirming the level of English language proficiency and the absence of obstacles to taking part in the study. They used a personal computer with the pre-installed computer system "Longitude" (Software Longitude, Version 19, production of LLC "Longitude", St. Petersburg, Russia) [42] a software elaborated for automated stimuli exposition in a randomized order during psychological experiments, in our case allowing the mathematical data collection on the accuracy, speed and errors of each stimulus recognition for each participant. As soon as participants completed the experimental session, each participant sent the file with his/her results by email to the research group. After checking the time and the date of the session completion and the absence of repeated attempts to pass the session (learning control and biased data), the participant received financial compensation. Data analysis was performed using the IBM SPSS Statistics 25 (IBM Corp., released 2017, IBM SPSS Statistics for Windows, Version 25.0, Armonk, NY, USA). The performance measures were response time, number of error responses, and number of delayed responses. The distribution of the measures for iconic words at four different SDs, non-iconic words and non-words were compared using the chi-square test. To compare the time of reaction, the mean reaction time for iconic and non-iconic words was calculated for each participant; the repeated measures design was used for this purpose. The Student's t-test for dependent samples was used to make the comparison. To check the influence of the stage of de-iconization of the stimuli on the time taken to recognize them, the generalized linear model (GLM) repeated measures procedure was used. To determine the differences between the time of the reaction to non-iconic and iconic words, the simple contrast method was used.

The participants were presented with visual instructions on the screen. Their task was to identify, as quickly and accurately as possible, whether the visually presented stimulus was either a word or non-word by correspondingly pressing one of the two designated buttons on the keyboard. The training session, where participants worked through 10 words and 10 non-words presented in random order, preceded the experimental one. The experimental and control stimuli (non-imitative words and non-words) were presented in random order one by one on a PC screen with responses collected from the keyboard. A timeout was set at $1000 \mathrm{~ms}$.

\section{Results}

During the experiment, a total set of 6784 stimuli (32 target words $\times 106$ participants) was presented to all the participants. Table 3 and Figure 1 show the distributions of correct responses (true) and errors/delays for all the categories of stimuli-iconic words (SD-1 to SD-4), non-iconic words and non-words. 
Table 3. Crosstabulation table for "Parameter" $\times$ "Precision" $\times$ "Stimuli type".

\begin{tabular}{cccccc}
\hline \multirow{2}{*}{ Parameter } & & \multicolumn{3}{c}{ Precision } & \multirow{2}{*}{ Total } \\
\cline { 3 - 5 } & & Delay & True & Error & \\
\cline { 3 - 5 } Non-iconic words & Count & 103 & 2411 & 878 & 3392 \\
& $\%$ & $3.0 \%$ & $71.1 \%$ & $25.9 \%$ & $100.0 \%$ \\
\hline \multirow{2}{*}{ Non-words } & Count & 231 & 5180 & 1373 & 6784 \\
& $\%$ & $3.4 \%$ & $76.4 \%$ & $20.2 \%$ & $100.0 \%$ \\
\hline \multirow{2}{*}{ SD-1 } & Count & 33 & 440 & 375 & 848 \\
& $\%$ & $3.9 \%$ & $51.9 \%$ & $44.2 \%$ & $100.0 \%$ \\
\hline \multirow{2}{*}{ SD-2 } & Count & 31 & 496 & 321 & 848 \\
& $\%$ & $3.7 \%$ & $58.5 \%$ & $37.9 \%$ & $100.0 \%$ \\
\hline \multirow{2}{*}{ SD-3 } & Count & 34 & 577 & 237 & 848 \\
& $\%$ & $4.0 \%$ & $68.0 \%$ & $27.9 \%$ & $100.0 \%$ \\
\hline \multirow{2}{*}{ SD-4 } & Count & 33 & 525 & 290 & 848 \\
& $\%$ & $3.9 \%$ & $61.9 \%$ & $34.2 \%$ & $100.0 \%$ \\
\hline \multirow{2}{*}{ SDs in total } & Count & 131 & 2038 & 1223 & 3392 \\
& $\%$ & $3.9 \%$ & $60.1 \%$ & $36.1 \%$ & $100.0 \%$ \\
\hline
\end{tabular}

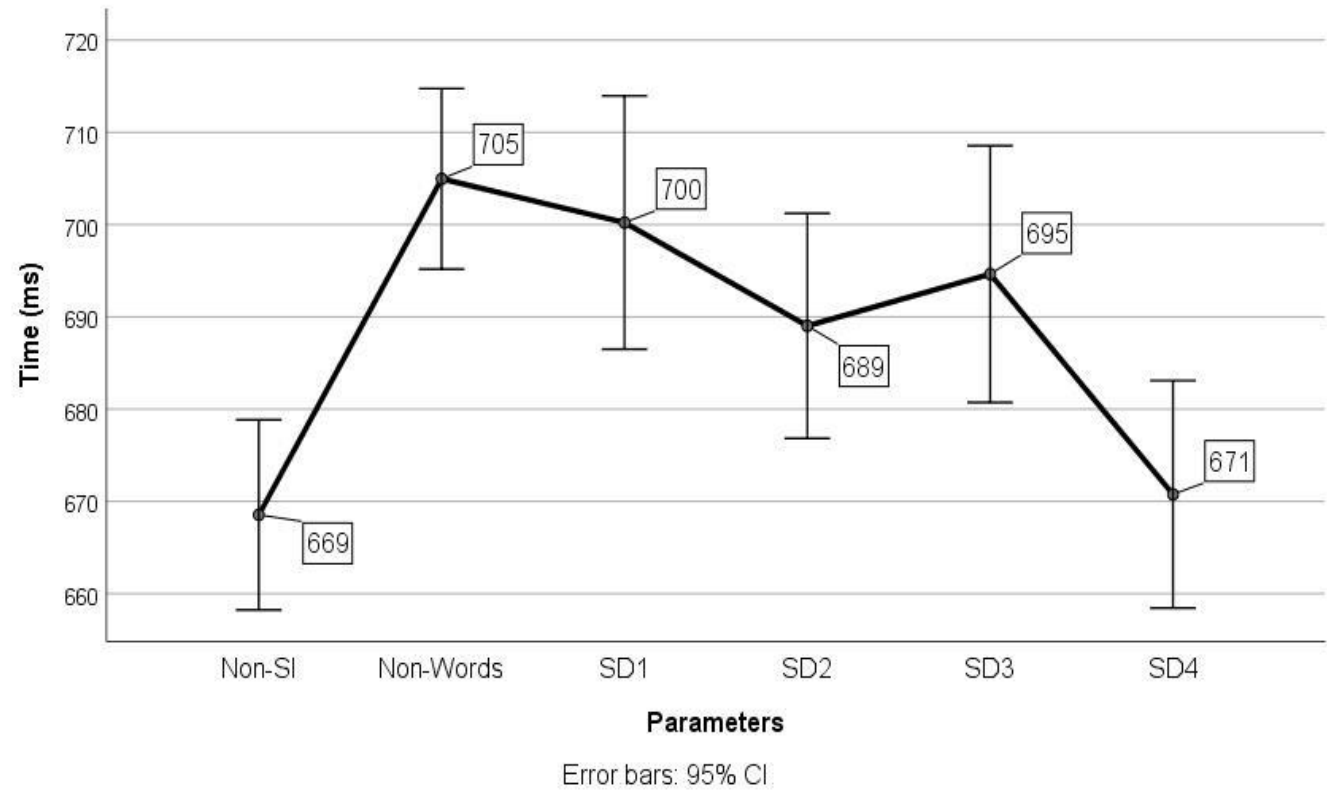

Figure 1. Word recognition time (in ms) depending on the type of stimuli.

The difference in response accuracy between iconic and non-iconic words is statistically significant $\left(\chi^{2}(2, \mathrm{~N}\right.$ [In this case $\mathrm{N}$ is an amount of reactions (see Table 3$)$. The number of participants is $\mathrm{N}=106]=6784)=91.274, p<0.0001)$; the response accuracy for iconic words is lower than that for non-iconic words. The effect was tested for each of the four types of SD stimuli. It turned out to be statistically significant for the groups SD-1 ( $\mathrm{X}^{2}(2$, $\mathrm{N}=4240)=115.90, p<0.0001), \mathrm{SD}-2\left(\mathrm{X}^{2}(2, \mathrm{~N}=4240)=50.872, p<0.0001\right)$, and SD-4 $\left(\mathrm{X}^{2}(2\right.$, $\mathrm{N}=4240)=26.803, p<0.0001)$. For the group SD-3, the result is not statistically significant $\left(X^{2}(2, N=4240)=3.974, p=0.137\right)$. All four groups of iconic words differ significantly from each other in terms of response accuracy $\left(X^{2}(6, N=3392)=52.113, p<0.0001\right)$; SD-3 words have the highest response accuracy rate $(68.0 \%)$, SD-1-the lowest one $(51.9 \%)$.

The response accuracy for non-words was compared with that for both iconic and non-iconic word groups. The response accuracy for non-words turned out to be higher than that for both iconic $\left(\mathrm{X}^{2}(2, \mathrm{~N}=10,176)=307.507, p<0.0001\right)$ and non-iconic words $\left(X^{2}(2, N=10,176)=41.961, p<0.001\right)$. We used a repeated measures design to calculate 
the mean reaction time for iconic and non-iconic words for each participant. Only correct responses were included into the model. Table 4 presents the results of the paired samples $\mathrm{t}$-test; the difference between the two groups is statistically significant $(\mathrm{t}=6.296 ; \mathrm{df}=105$; $p<0.0001$ ).

Table 4. Descriptive statistics for reaction time for iconic (SD) and non-iconic words.

\begin{tabular}{ccccc}
\hline Pair 1 & Mean & N & Std. Deviation & Std. Error Mean \\
\hline Time_words & 668.5329 & 106 & 53.49722 & 5.19611 \\
Time_SD & 688.6590 & 106 & 52.48430 & 5.09773 \\
\hline
\end{tabular}

To control the effect of the type of SD-stimuli (parameter) on word recognition time, the generalized linear model (GLM) repeated measures procedure was used; we fitted the model with the fixed factor parameter (5 levels: non-iconic words, SD-1, SD-2, SD-3, SD-4) and time (ms) as a dependent variable (see Table 5).

Table 5. Mean recognition time (in $\mathrm{ms}$ ) and standard deviation for different stimuli types.

\begin{tabular}{cccc}
\hline Type of Stimuli & Mean & Std. Deviation & N \\
\hline Non-iconic words & 668.5329 & 53.49722 & 106 \\
Non-words & 688.6590 & 52.48430 & 106 \\
SD-1 & 700.2173 & 71.27646 & 106 \\
SD-2 & 689.0211 & 63.36702 & 106 \\
SD-3 & 694.6380 & 72.27386 & 106 \\
SD-4 & 670.7598 & 64.02504 & 106 \\
\hline
\end{tabular}

A statistically significant main effect for the parameter was found $(\mathrm{F}(4 ; 102)=15.987$; $p<0.0001)$. The time of stimuli recognition significantly depends on the stimulus type. The effect is large: partial eta-squared $=0.385$, explaining $38.5 \%$ of the reaction time variance.

Figure 1 demonstrates the mean time (in ms) of word recognition for all stimuli groups, including non-words. The word recognition time increases with the increase in the iconicity of a word, i.e., the more iconic a word is, the slower the recognition time. To determine the differences between the time of the reaction to non-iconic (Non-SI as indicated on Figure 1) and iconic words, the simple contrast method was used, comparing the first level of the factor parameter (words) with each of the subsequent levels (SD-1, SD-2, SD-3, SD-4). The results are shown in Table 6.

Table 6. Comparison of the reaction time for words and target stimuli.

\begin{tabular}{ccccccc}
\hline \multicolumn{7}{c}{ Tests of Within-Subjects Contrasts } \\
\hline Parameters & $\begin{array}{c}\text { Type III Sum } \\
\text { of Squares }\end{array}$ & df & Mean Square & F & Sig. & $\begin{array}{c}\text { Partial } \\
\text { Eta-Squared }\end{array}$ \\
\hline SD-1 & $106,413.288$ & 1 & $106,413.288$ & 26.847 & 0.000 & 0.204 \\
SD-2 & $44,495.353$ & 1 & $44,495.353$ & 18.244 & 0.000 & 0.148 \\
SD-3 & $72,236.463$ & 1 & $72,236.463$ & 30.501 & 0.000 & 0.225 \\
SD-4 & 525.671 & 1 & 525.671 & 0.177 & 0.674 & 0.002 \\
\hline
\end{tabular}

Thus, the time of the reaction to groups SD-1, SD-2, SD-3 is significantly longer than that to non-iconic words; the time of the reaction to SD-4 is not significantly different from that to non-iconic words.

The time of the reaction to the group of non-words was compared with that to groups of iconic and non-iconic words. The GLM repeated measures and the simple contrast method were applied to compare the first level of the factor parameter (non-words) with the other five groups (non-iconic words, SD-1, SD-2, SD-3, SD-4). Table 7 demonstrates the significant effects for groups of non-iconic words, SD-2 and SD-4 words. 
Table 7. Comparison of the reaction time for non-words and target stimuli.

\begin{tabular}{ccccccc}
\hline \multicolumn{7}{c}{ Tests of Within-Subjects Contrasts } \\
\hline Parameters & $\begin{array}{c}\text { Type III Sum } \\
\text { of Squares }\end{array}$ & df & Mean Square & F & Sig. & $\begin{array}{c}\text { Partial } \\
\text { Eta-Squared }\end{array}$ \\
\hline Words & $140,677.420$ & 1 & $140,677.420$ & 71.927 & 0.000 & 0.407 \\
SD-1 & 2387.240 & 1 & 2387.240 & 0.511 & 0.476 & 0.005 \\
SD-2 & $26,938.877$ & 1 & $26,938.877$ & 8.328 & 0.005 & 0.073 \\
SD-3 & $11,300.002$ & 1 & $11,300.002$ & 2.753 & 0.100 & 0.026 \\
SD-4 & $124,004.242$ & 1 & $124,004.242$ & 27.187 & 0.000 & 0.206 \\
\hline
\end{tabular}

The mean reaction time for the group of non-words is significantly longer than that for the groups of SD-2 and SD-4 words; the mean reaction time for the groups of SD-1 and SD-3 words, however, is not significantly different from that of non-words.

\section{Discussion}

In this study, we used 32 key stimuli to investigate how Russian speakers perceive visually presented English iconic words at different de-iconization stages in comparison with non-iconic words and non-words. Our original research hypotheses were supported as we learnt that iconic words differ from non-iconic words in the speed and accuracy of their perception; iconic words at different de-iconization stages are recognized with different speed and accuracy; non-words, iconic words at different de-iconization stages, and noniconic words are perceived differently by L2 learners. The conducted psycholinguistic experiment led to the following major findings:

(1) Visually presented iconic words exhibit a significant difference from non-iconic words in their recognition by the research participants;

(2) There is an interdependence between the SDs of iconic words and such parameters as the speed and accuracy of their recognition;

(3) The gradation between the least and the most de-iconized iconic words is perceived by non-native speakers, which may affect $\mathrm{L} 2$ acquisition.

Finding 1: Visually presented iconic words exhibited a significant difference from non-iconic words in their perception by the research participants. As demonstrated by Figure 1 and Table 5, iconic words (at all SDs) differ from non-iconic ones in the way they are perceived. Our previous research on visual perception of iconicity, by the method of lexical decision, also revealed a statistically verified difference in speed and accuracy of recognition of iconic and non-iconic words in favor of the latter [23]. We interpreted these results as being the consequence of the cognitive complexity of the processing of iconic stimuli. However, we did not consider SDs in our analysis, which could have influenced the results as a confounding variable. Indeed, the findings of the present study have demonstrated a direct connection between a word recognition time and its iconic features.

We suggest the following explanation for the observed tendency of delay in the recognition of iconic words. The first factor at play might be the cognitive mechanisms of visual perception of iconic stimuli. Traditionally, these mechanisms are explained by synesthesia and cross-modality conceptions [43-45]. However, these conceptions could be fully applicable to the interpretation of the results of the experiments focusing on the auditory, not visual perception of iconic words [46]. In addition, Deroy and Spence argue that synesthesia could hardly be coordinated with other cross-modal correspondences [47]. This supports the assumption that visual cognitive processing of semantic and sensual information could compete [48].

Furthermore, such factors as the previous linguistic and language learning experience of the recipients might have influenced visual recognition of iconicity as well. In our experiment, iconic words were, in general, less frequent (0.222) than non-iconic ones (0.8). Not only are they not commonly found in general texts types, but they also might go beyond the lexical experience of the participants. As speakers of other languages, they 
had little chance to see English iconic words in writing before the experiment, not only for the reason of lower frequency of iconic words, but also because of iconicity itself. Being iconic and, therefore, expressive, such words are more common in oral than in written speech. Moreover, iconic words, if they do appear in literature, are often used not to convey a particular meaning, but to create special emotive coloration [49]. This might account for increased time and inaccuracy in the recognition of iconic words in comparison with non-iconic ones. This could be explained by the fact that words containing complex or inconsistent matches between spelling and sound are harder to read than words where these conformities are traditional and familiar for a reader [50].

Conversely, non-iconic words were recognized faster and with lower error rates. It is noteworthy that reading is a skill automatized in the process of training; reading skills and ability to recognize written words improve with the expansion of the learner's vocabulary [51]. It is in line with the orthographic prediction error model, which describes the dependence of visual recognition on the internal (i.e., contingent on the previous knowledge or the context) visual orthographic expectations based on a rather extensive lexicon [52]. Furthermore, the high reading speed in adults (suggesting the high efficiency of the visual and orthographic processing of words) is argued to be based on the system of prognostic coding [53]. These factors might have accelerated the recognition of noniconic words, that might be more familiar to the participants. It should be noted that in the process of language evolution, imitative words, along with the loss of iconicity, acquire typical spelling structures, so that in the process of their identification, there is no mismatch between spelling and pronunciation. It is known that word recognition refers to the processes of understanding sounds and meanings of words and assumes the extraction of phonological information [54]. In our case, words related to SD-4 and non-imitative words are comparable in the parameters of typical spelling and semantic structures, which determines the relatively high speed of their recognition.

To summarize, there could be two major reasons why Russian speakers perceive visually presented English iconic words more slowly and less precisely than non-iconic ones. First, cognitive mechanisms of processing semantic and sensual information in iconic words presumably compete. Second, iconic words normally fall outside the written receptive vocabulary size of language learners, which impedes the recognition of such words. To further explore this effect, we looked at the peculiarities of the perception of iconic words at different SDs.

Finding 2: There is a correlation between de-iconization stages of iconic words and such parameters as the speed of recognition and the number of mistakes. The most iconic (the least de-iconized) imitative words at SD-1 were characterized by the lowest accuracy rate and the longest recognition time. The less iconic (more de-iconized) words (SD-2, SD-3, SD-4) were recognized more accurately and faster, the results improving in accordance with their SD. Thus, the comparison within the group of iconic words revealed the following tendency: the higher the de-iconization stage of a word is, the faster and more accurately it is recognized (the best results were shown by SD-3 and SD-4 groups; the worst results were shown by SD-1 words-see Table 4). Overall, the speed of recognition was the highest for non-iconic words and SD-4 iconic words, the lowest for non-words and SD-1 words (see Figure 1, Table 7).

This effect could be explained by the diachronic (historical) development of iconic words. Once coined, they have to be integrated into the language system in order to function as its elements. The integration takes place at all levels-phonological (acquiring conventional phonetic structure), morphological (acquiring inflectional morphology or becoming a content part of speech — verb, noun, adjective, etc.-by conversion), and syntactic (acquiring a syntactic function in a sentence). Poorly integrated imitative words are interjections (or ideophones-in some languages [2]) often exhibiting violation of phonotactic, phonological, etc., rules of a given language [5,55]. For this reason, SD-1 words are less likely to come up in formalized written context than more de-iconized words in the same frequency band. They rather occur in the periphery genres of written 
language-fairy tales [8], comic books [56], fiction and fantasy novels [57]. Thus, the scope of expected previous reading experience of the respondents might have included very few SD-1 words, which hinders their visual recognition.

Once integrated, iconic words become subjected to all diachronic rules of a particular language. Regular sound changes modify their form, and semantic shifts expand, transform, and diffuse their meaning. Whereas for a non-iconic word such changes make no difference (symbolic, conventional words remain symbolic and conventional in their essence no matter how many form and meaning changes they have undergone), as these changes weaken and finally eliminate the iconic form-meaning correlation in imitative words. The latter cease to be iconic and become non-iconic.

The research revealed that the results of this gradual, step-by-step evolution are clearly noticeable today. Our participants exhibited the recognition of this fundamental evolutionary process (which is particularly well illustrated by Figure 1). Our results revealed a clear tendency: the word recognition time increases with the increase in word iconicity, SD-1 words are closest in this parameter to non-words.

All non-words used in the experiment are potential words of a language- they have a phonologically legal form but no meaning. SD-1 words have their meaning 'born' from their form (a strong iconic form-meaning association) and they are the novel elements still being introduced to the language. Hence, we can draw a certain similarity between them and non-words, which was corroborated by the results of the experiment. SD-2 words (buzz, hiss) are content words (verbs, nouns) - they are fully systemic (they have inflectional morphology and syntactic function in a sentence) and, at the same time iconic (they are perceived as 'expressive' and 'depictive'). The better accuracy and speed of recognition of SD-2 words compared to SD-1 words illustrates this transition. Historically, the longer an iconic word exists in the language, the less iconic it becomes-the iconic form-meaning correlation is being distorted by form changes (regular sound shifts $\mathrm{OE}$ hlahhan > ModE laugh/la:f/) and meaning changes (clock 'a hitting sound' > 'an object'). SD-4 words (like touch) become indistinguishable from non-iconic words (sock, twig), which is supported by the experiment results as well.

Thus, Figure 1 illustrates the phylogenic, evolutionary development of iconic words, which is a gradual de-iconization (loss of iconic qualities in favor of symbolic, conventional ones). The findings of the present study have demonstrated that the outcomes of this ongoing, evolutionary process are clearly perceived by the respondents, and iconic words differ by de-iconization stages not only theoretically, but also empirically.

Finding 3: The gradation between the least and the most de-iconized imitative words is perceived by non-native speakers which may affect L2 acquisition. The experiment results also demonstrated the universal nature of iconic words. Not only did native speakers of Russian perceive iconic words differently from non-iconic ones (finding 1), but they were also able to distinguish the subtle differences between their de-iconization stages (finding 2). Yet, they had neither prior knowledge of the words' etymologies, nor exposure to English iconic words in their childhood. Thus, the inclusion of iconic words in foreign language input (on condition that their de-iconization stage is taken into account) is likely to prove effective. For instance, audially perceived iconic words, compared with non-iconic ones, are more easily acquired by language learners, as iconic sound-meaning mapping facilitates the logical as well as intuitional understanding (and memorizing) of meaning [25,58]. This is predetermined by the logic of first language acquisition, iconicity being a fundamental stage of language ontogeny [59].

Altogether, there are two main arguments for including iconicity into foreign language teaching: (1) the ease of memorization of iconic words due to their expressivity and their ability to trigger the interference of meaning from the word form; (2) their impact on the acquisition of non-iconic words [19]. Previous research has revealed the role of iconicity in language acquisition. However, it has focused mostly on first language acquisition (FLA), while the role of iconicity in the area of second/foreign language acquisition remains poorly understood. Interestingly, whereas the group of most iconic words (SD-1) facilitates 
the FLA process, it presents a certain difficulty for second/foreign language learners, as demonstrated by the results of our study.

The observed effect could be partly explained by Krashen's Acquisition-Learning Hypothesis [60]. The role of linguistic input in FLA is dominant for language development, i.e., children need to receive enough language input to acquire and learn their L1. The fact is, that iconic vocabulary constitutes an essential part of this input, which is provided only orally at the earliest stages of language acquisition. Children learn such words with ease as the phonetic form of a word is directly linked with its meaning. Moreover, it was shown that sound symbolism significantly improved the children's' ability to encode the semantic representation of the novel verb and facilitated long-term retention of novel verbs [61]. Gradually, iconic vocabulary diminishes at a later stage of language development, giving way to less iconic and more arbitrary lexis with its conceptualized learning. We assume that most iconic words (SD-1) turned out to be the most difficult to process, as indicated by the lowest accuracy and reaction speed because of their marginal status within the sound-symbolic system of a language from both the syntactic and semantic perspectives.

Our findings raise a question about the role of highly iconic (SD-1) words in foreign language acquisition. Not only do they not follow phonotactic constraints of a language, but they are also not syntactically related to other items. As opposed to them, less iconic words (SD-2-SD-4) are fully integrated into the language system. Still, they exhibit a certain symbolism, i.e., their form reflects a meaning, for example, some consonant clusters refer to certain properties. At the initial stage of English language learning, we suggest including iconic words at the middle SDs (SD-2, to a lesser extent, SD-3). For example, monosyllabic words with consonant clusters (phonaesthemes) have an expressive meaning (e.g., splreflects suddenness, fl- is associated with quick, light movements, gl- refers to shining visual phenomena). Phonetic training may also involve forming an association between certain sounds and some elements or features (size, shape, etc.). As gestures complement language development at the early stages of L1 learning, we also suggest performing iconic gestures during the process of introduction and acquisition to new lexical items in a foreign language classroom. As mentioned earlier, our findings suggest that the introduction of the visually presented iconic words might be effective in L2 teaching and learning, but only provided that the variation according to SDs is accounted for.

\section{Conclusions}

The results of the present research have added to our understanding of cognitive mechanisms of the visual perception of imitative words. To maximize the reliability of the results, we increased the number of stimuli pairs from 40 (in our previous research) to 64. We have obtained empirical evidence that the degrees of English words de-iconization are recognized by Russian speakers. There is a statistically significant difference between iconic and non-iconic words, and non-words in terms of recognition time and accuracy rates. Moreover, there is a clear correlation between these parameters and iconic words' SDs. This partly supports our hypothesis about the importance of taking into account SDs of iconic words in L2 teaching and learning. Our further research is aimed to study the recognition of Russian and English iconic words at different SDs by the respective native speakers, as well as the neuronal basis of iconic words processing using EEG.

\section{Limitations}

The present study has certain linguistic imitations. The pre-selection of the research material is based on the data obtained from etymological dictionaries. The method of the diachronic evaluation of the imitative lexicon is fully applicable only to languages with a well-recorded history. Words on SD-4 are "old" words which have lost both their original form and meaning, and in modern synchrony they are indistinguishable from non-imitative words. Thus, they are more likely to be detected in well-documented languages than in languages with no written history. 
There are another two limitations in this study that could be addressed in future research. Although the focus of our investigation was on Russian L2 learners, and we had a large sample size of participants so that the results may be generalizable to other native speakers, no control group of English native speakers was recruited. Next, given the general low frequency of the written form of iconic words, future studies may regard the possibility of stimulus presentation by combining both visual and auditory stimuli.

Author Contributions: Conceptualization, M.F. and L.T.; methodology, L.T.; software, L.T.; validation and formal analysis, A.N.; investigation, Y.S.; resources, Y.L.; data curation, A.N.; writing-original draft preparation, L.T., M.F., A.N., Y.S. and Y.L.; writing-review and editing, Y.S. and Y.L.; visualization, A.N.; supervision, L.T.; project administration, L.T.; funding acquisition, L.T. All authors have read and agreed to the published version of the manuscript.

Funding: This research was funded by RFBR, grant No. 20-013-00575 “Psychophysiological indicators of the perception of sound symbolic words in native and foreign languages".

Institutional Review Board Statement: Ethical review and approval were waived for this study, due to no disclosure of any personal information.

Informed Consent Statement: Written informed consent was obtained from all subjects involved in the study.

Data Availability Statement: Data supporting results can be found here: https:/ /drive.google.com/ drive/folders/1r7d8WJCydHMLbN2kLw1ZdAeUd9kNL5s-?usp=sharing.

Conflicts of Interest: The authors declare no conflict of interest. The funders had no role in the design of the study; in the collection, analyses, or interpretation of data; in the writing of the manuscript, or in the decision to publish the results.

\section{References}

1. Bergen, B.K. The Psychological Reality of Phonaesthemes. Language 2004, 80, 290-311. [CrossRef]

2. Voeltz, E.F.K.; Kilian-Hatz, C. (Eds.) Ideophones. Typological Studies in Language; John Benjamins Publishing Company: Amsterdam, The Netherlands, 2001.

3. Hockett, C.F. The origin of speech. Sci. Am. 1960, 203, 89-96. [CrossRef]

4. Dingemanse, M. Redrawing the margins of language: Lessons from research on ideophones. Glossa A J. Gen. Linguist. 2018, 3, 4. [CrossRef]

5. Akita, K.; Pardeshi, P. (Eds.) Ideophones, Mimetics and Expressives; John Benjamins Publishing Company: Amsterdam, The Netherlands, 2019.

6. Hinton, L.; Nichols, J.; Ohala, J.J. (Eds.) Sound Symbolism; Cambridge University Press: Cambridge, MA, USA, 1994.

7. Flaksman, M.A. Iconic treadmill hypothesis-The reasons behind continuous onomatopoeic coinage. In Dimensions of Iconicity (ILL 15); Matthias, B., Zirker, A., Fischer, O., Ljungberg, C.H., Eds.; John Benjamins Publishing Company: Amsterdam, The Netherlands, 2017; pp. 15-38. [CrossRef]

8. Shamina, E.A. Iconicity in English literary neologisms (based on R. Dahl's fairy tale the BFG). In Dimensions of Iconicity (ILL 15); Matthias, B., Zirker, A., Fischer, O., Ljungberg, C.H., Eds.; John Benjamins Publishing Company: Amsterdam, The Netherlands, 2017; pp. 85-96. [CrossRef]

9. Asano, M.; Imai, M.; Kita, S.; Kitajo, K.; Okada, H.; Thierry, G. Sound symbolism scaffolds language development in preverbal infants. Cortex 2015, 63, 196-205. [CrossRef] [PubMed]

10. Imai, M.; Kita, S. The sound symbolism bootstrapping hypothesis for language acquisition and language evolution. Philos. Trans. R. Soc. B Biol. Sci. 2014, 369, 20130298. [CrossRef] [PubMed]

11. Perry, L.K.; Perlman, M.; Winter, B.; Massaro, D.W.; Lupyan, G. Iconicity in the speech of children and adults. Dev. Sci. 2017, 21, e12572. [CrossRef]

12. Voronin, S.V. Osnovy Fonosemantiki [The Fundamentals of Phonosemantics], 2nd ed.; Lenand: Moscow, Russia, 2006.

13. Lockwood, G.; Hagoort, P.; Dingemanse, M. How Iconicity Helps People Learn New Words: Neural Correlates and Individual Differences in Sound-Symbolic Bootstrapping. Collabra 2016, 2. [CrossRef]

14. Revill, K.P.; Namy, L.L.; DeFife, L.C.; Nygaard, L. Cross-linguistic sound symbolism and crossmodal correspondence: Evidence from fMRI and DTI. Brain Lang. 2014, 128, 18-24. [CrossRef]

15. Nygaard, L.; Cook, A.E.; Namy, L.L. Sound to meaning correspondences facilitate word learning. Cognition 2009, 112, 181-186. [CrossRef]

16. Kovic, V.; Plunkett, K.; Westermann, G. The shape of words in the brain. Cognition 2010, 114, 19-28. [CrossRef]

17. Lockwood, G.; Dingemanse, M.; Hagoort, P. Sound-symbolism boosts novel word learning. J. Exp. Psychol. Learn. Mem. Cogn. 2016, 42, 1274-1281. [CrossRef] [PubMed] 
18. Blasi, D.E.; Wichmann, S.; Hammarström, H.; Stadler, P.F.; Christiansen, M.H. Sound-Meaning association biases evidenced across thousands of languages. Proc. Natl. Acad. Sci. USA 2016, 113, 10818-10823. [CrossRef] [PubMed]

19. Nielsen, A.; Dingemanse, M. Iconicity in Word Learning and Beyond: A Critical Review. Lang. Speech 2021, 64, 52-72. [CrossRef] [PubMed]

20. Reilly, J.; Westbury, C.; Kean, J.; Peelle, J.E. Arbitrary Symbolism in Natural Language Revisited: When Word Forms Carry Meaning. PLoS ONE 2012, 7, e42286. [CrossRef]

21. Monaghan, P.; Fletcher, M. Do sound symbolism effects for written words relate to individual phonemes or to phoneme features? Lang. Cogn. 2019, 11, 235-255. [CrossRef]

22. Flaksman, M.A. Diachronicheskoye Razvitie Zvuloizobrazitelnoi Leksiki Angliiskogo Yazika [Diachronic Development of English Iconic Vocabulary]. Ph.D. Thesis, University of St. Petersburg, St. Petersburg, Russia, 2015.

23. Tkacheva, L.O.; Sedelkina, Y.G.; Nasledov, A. Possible Cognitive Mechanisms for Identifying Visually-presented Sound-Symbolic Words. Psychol. Russ. State Art 2019, 12, 188-200. [CrossRef]

24. Moreno-Cabrera, J.C. Iconicity in Language: An Encyclopaedic Dictionary; Cambridge Scholars Publishing: Cambridge, UK, 2020.

25. Dingemanse, M.; Blasi, D.E.; Lupyan, G.; Christiansen, M.H.; Monaghan, P. Arbitrariness, Iconicity, and Systematicity in Language. Trends Cogn. Sci. 2015, 19, 603-615. [CrossRef]

26. Smith, L.; Yu, C. Infants rapidly learn word-referent mappings via cross-situational statistics. Cognition 2008, 106, 1558-1568. [CrossRef]

27. Ozturk, O.; Krehm, M.; Vouloumanos, A. Sound symbolism in infancy: Evidence for sound-shape cross-modal correspondences in 4-month-olds. J. Exp. Child Psychol. 2013, 114, 173-186. [CrossRef]

28. Tzeng, C.Y.; Nygaard, L.; Namy, L.L. Developmental change in children's sensitivity to sound symbolism. J. Exp. Child Psychol. 2017, 160, 107-118. [CrossRef] [PubMed]

29. Kantartzis, K.; Imai, M.; Kita, S. Japanese Sound-Symbolism Facilitates Word Learning in English-Speaking Children. Cogn. Sci. 2011, 35, 575-586. [CrossRef]

30. Namy, L.L.; Nygaard, L. Perceptual-motor constraints on sound-to-meaning correspondence in language. Behav. Brain Sci. 2008, 31, 528-529. [CrossRef]

31. Perry, L.K.; Perlman, M.; Lupyan, G. Iconicity in English and Spanish and Its Relation to Lexical Category and Age of Acquisition. PLoS ONE 2015, 10, e0137147. [CrossRef] [PubMed]

32. Lockwood, G.; Tuomainen, J. Ideophones in Japanese modulate the P2 and late positive complex responses. Front. Psychol. 2015, 6, 933. [CrossRef]

33. Shinohara, K.; Kawahara, S. A Cross-linguistic Study of Sound Symbolism: The Images of Size. Annu. Meet. Berkeley Linguist. Soc. 2010, 36, 396-410. [CrossRef]

34. Itagaki, S.; Murai, S.; Kobayasi, K.I. Brain Activity Related to Sound Symbolism: Cross-modal Effect of an Aurally Presented Phoneme on Judgment of Size. Sci. Rep. 2019, 9, 7017. [CrossRef] [PubMed]

35. Aryani, A.; Jacobs, A.M. Affective Congruence between Sound and Meaning of Words Facilitates Semantic Decision. Behav. Sci. 2018, 8, 56. [CrossRef]

36. Mattes, V. Iconicity in the lexicon. Stud. Lang. 2017, 41, 813-842. [CrossRef]

37. Perlman, M.; Lupyan, G. People Can Create Iconic Vocalizations to Communicate Various Meanings to Naïve Listeners. Sci. Rep. 2018, 8, 1-14. [CrossRef]

38. Aryani, A.; Conrad, M.; Schmidtke, D.; Jacobs, A. Why 'piss' is ruder than 'pee'? The role of sound in affective meaning making. PLoS ONE 2018, 13, e0198430. [CrossRef]

39. Motamedi, Y.; Little, H.; Nielsen, A.; Sulik, J. The iconicity toolbox: Empirical approaches to measuring iconicity. Lang. Cogn. 2019, 11, 188-207. [CrossRef]

40. Meyer, D.E.; Schvaneveldt, R.W. Facilitation in recognizing pairs of words: Evidence of a dependence between retrieval operations. J. Exp. Psychol. 1971, 90, 227-234. [CrossRef] [PubMed]

41. Guo, Y.; Logan, H.L.; Glueck, D.H.; Muller, K.E. Selecting a sample size for studies with repeated measures. BMC Med. Res. Methodol. 2013, 13, 100. [CrossRef]

42. Ivanova, A.E.; Miroshnikov, S.A. Metodicheskie Materialy k Ekspertnoi Sisteme Individual'nogo Soprovozhdeniya «Longityud» [Methodical Materials for the Expert System of Individual Tracking «Longitude»]; St. Petersburg State University Press: St. Petersburg, Russia, 2001.

43. Ramachandran, V.S.; Hubbard, E.M. Synaesthesia-A window into perception, thought and language. J. Conscious. Stud. 2001, 8, 3-34.

44. Spence, C. Crossmodal correspondences: A tutorial review. Atten. Percept. Psychophys. 2011, 73, 971-995. [CrossRef]

45. Cuskley, C.; Kirby, S. Synesthesia, cross-modality, and language evolution. In Oxford Handbook of Synesthesia; Simner, J., Hubbard, E., Eds.; Oxford University Press: Oxford, UK, 2013; pp. 869-899.

46. Parise, C.V. Crossmodal Correspondences: Standing Issues and Experimental Guidelines. Multisens. Res. 2016, $29,7-28$. [CrossRef] [PubMed]

47. DeRoy, O.; Spence, C. Lessons of synaesthesia for consciousness: Learning from the exception, rather than the general. Neuropsychologia 2016, 88, 49-57. [CrossRef] [PubMed]

48. Yap, M.J.; Balota, D.A. Visual Word Recognition; Oxford University Press: Oxford, UK, 2015. 
49. Ebzeeva, Y.N.; Lenko, G.N.; Dubinina, N.V. Graphic Realization of Phonetic Expressive Means of Emotivity (Based on the Works of Fiction of Modern French, English and German Authors). Mediterr. J. Soc. Sci. 2015, 6, 258. [CrossRef]

50. Zevin, J. Word Recognition. In Encyclopedia of Neuroscience; Elsevier: Amsterdam, The Netherlands, 2009; pp. 517-522.

51. Kazanina, N.; Phillips, C.; Idsardi, W. The influence of meaning on the perception of speech sounds. Proc. Natl. Acad. Sci. USA 2006, 103, 11381-11386. [CrossRef]

52. Gagl, B.; Sassenhagen, J.; Haan, S.; Gregorova, K.; Richlan, F.; Fiebach, C.J. An orthographic prediction error as the basis for efficient visual word recognition. NeuroImage 2020, 214, 116727. [CrossRef]

53. Price, C.J.; Devlin, J. The Interactive Account of ventral occipitotemporal contributions to reading. Trends Cogn. Sci. 2011, 15, 246-253. [CrossRef] [PubMed]

54. Koda, K. Word Recognition; Cambridge University Press (CUP): Cambridge, MA, USA, 2005; pp. $29-47$.

55. Dingemanse, M. Making new ideophones in Siwu: Creative depiction in conversation. Pragmat. Soc. 2014, 5, 384-405. [CrossRef]

56. Taylor, K.J. KA-BOOM! A Dictionary of Comic Book Words, Symbols and Onomatopoeia; Mora Publications: Surrey, BC, USA, 2007.

57. Davydova, V.A. Sound symbolism in invented languages. In Anglistics of the XXI Century, Phonosemantics; Flaksman, M.A., Brodovich, O.I., Eds.; St. Petersburg State University Press: St. Petersburg, Russia, 2016; Volume 2, pp. 32-39.

58. Perniss, P.; Vigliocco, G. The bridge of iconicity: From a world of experience to the experience of language. Philos. Trans. R. Soc. B Biol. Sci. 2014, 369, 20130300. [CrossRef] [PubMed]

59. Imai, M.; Kita, S.; Nagumo, M.; Okada, H. Sound symbolism facilitates early verb learning. Cognition 2008, 109, 54-65. [CrossRef] [PubMed]

60. Bernhardt, E.B.; Krashen, S.D. Second Language Acquisition and Second Language Learning. Mod. Lang. J. 1989, 73, 483. [CrossRef]

61. Kantartzis, K.; Imai, M.; Evans, D.; Kita, S. Sound Symbolism Facilitates Long-Term Retention of the Semantic Representation of Novel Verbs in Three-Year-Olds. Languages 2019, 4, 21. [CrossRef] 